\title{
Redesigning an experimentation course with PBL pedagogy to support accreditation in China
}

\section{Dr. Lijun Zhang, Beijing Institute of Technology}

associate professor of teaching in the School of Optics and Photonics of Beijing Institute of Technology (BIT) in China. She received her Ph.D. in Optical Engineering from Beijing Institute of Technology. Her research interests situate in Engineering Education. Now she is working on a research about constructing the practical curriculum system with the Outcome-Based Education (OBE) method to support the engineering education in BIT and the Engineering Education Program Accreditation in China, and working on a research about constructing university-industry cooperation internship platform to improve the problem-solving skills of professional degree master based on PBL mode as well.

\section{Dr. Dongxiao Wang, Opto-photonics School of Beijing Institute of Technology}

Wang Dongxiao, associate professor, Ph.D. Opto-photonics School of Beijing Institute of Technology (BIT). Her research interests include the reform of engineering practice education and teaching, and the innovation and entrepreneurship education. She mainly teaches 8 experimental-related public elective courses, with an average of 800 students per year, covering 44 engineering majors in 14 schools. Besides, she instructed students to accomplish more than 40 various types of scientific and technological innovation projects, 6 of which won the first prize in China. Moreover, he won the first prize of the Beijing Teaching Achievement Award in China. In addition, he published 12 papers and obtained 6 invention patents.

\section{Dr. Xiaofeng Tang, The Ohio State University}

Xiaofeng Tang is an Assistant Professor of Practice in the Department of Engineering Education at the Ohio State University. He worked as a postdoctoral fellow in engineering ethics at Penn State University. He received his Ph.D. in Science and Technology Studies from Rensselaer Polytechnic Institute.

\section{Prof. Zhonglian Zhang, Beijing Institute of Technology \\ Prof. Hai Lin, BeiJing Institute of Technology}

Professor Hai Lin is the Deputy Director of the Undergraduate Education Office of Beijing Institute of Technology, whose duty is Management of Engineering Education Accreditation, Undergraduate Programs, and Curriculums. He received his Ph.D. in Aircraft Design from Beijing Institute of Technology, and he worked successively as a teacher in the School of Aerospace Engineering of Beijing Institute of Technology, and the Director of Graduate Education Office in charge of Master \& Ph.D. Programs, Curriculums, and Graduate Education Projects. 


\title{
Redesigning an experimentation course with PBL pedagogy
}

\author{
to support accreditation in China
}

\begin{abstract}
:
This paper reports the redesign of a junior level engineering experimentation course to promote students' problem solving and technical communication skills. The redesign was carried out to support the accreditation of an engineering program in a technical institution in China.
\end{abstract}

Since China became an official member of the Washington Accord in 2016, engineering programs in Chinese universities and colleges have attempted to adopt outcome-based education. Between 2018 and 2019, the authors redesigned an experimentation course that had been offered for 14 years at the authors' home institution. The newly designed curriculum was implemented for the first time in the fall semester of 2019.

Following the guiding principle of letting students "work as an engineer," the course instructors took a backward design approach to redesign this course. First, learning outcomes for the course were redefined to highlight problem-solving skills, which are essential outcomes according to the ABET criteria. Second, a comprehensive assessment plan was created to measure student progress in each of the learning outcomes. Rubrics-based grading focuses on assessing five dimensions of student work: the solution's efficacy, quality of technical writing, oral communication, completion of prototypes, and testing plans and results. Finally, the newly developed learning outcomes and assessment plan were aligned with learning activities in the course, including design, prototyping, testing, as well as reflective exercises. Problem-Based Learning is the signature pedagogy in this course. The instructors also created an authentic learning environment, equipped with necessary sensors, electronic components, assembling materials, operating tools, and testing platforms.

Results of student learning in this course are reported in two manners: First, statistics of student grades in communication and hands-on work are shared. Second, we report results from a student survey that represents their self-assessment of problem-solving skills.

This work is important as it reports one of the few examples of systematically applying PBL and the ABET criteria in redesigning an engineering experimentation course in China. The paper discusses lessons from adopting ABET student outcomes in an international context and provides a case study for the international dissemination of educational standards in engineering.

\section{Introduction}


As problem-solving skills are considered the essential element of ABET accreditation criteria, the authors redesigned an experimentation course in a technology institute in northern China to support the program accreditation and improve engineering graduates' problem-solving skills.

The core idea of the redesign is to improve problem-solving skills and other necessary skills, such as technical communication and practical operation, through completing an authentic engineering project. While the redesigned course is contextualized inside a project-based framework, Problem-Based Learning (PBL) is the signature pedagogy for organizing the instruction. Specifically, the semester-long project was divided into several problems. Students ultimately completed the project step by step in the process of solving these problems.

Following the backward design process [1], the authors refined 5 learning outcomes from ABET criteria firstly and then designed a comprehensive assessment plan including direct assessment and indirect assessment corresponding to each learning outcome. Lastly, the authors designed instructional activities in class and after class assignments based on the learning outcomes and assessment plan.

The course's signature characters include problem-based learning, driven by hands-on problem solving and just-in-time scaffolding lectures, and portfolio-based assessment using student written reports and artifacts. The instructors also created an authentic learning environment, equipped with necessary sensors, electronic components, assembling materials, operating tools, and testing platforms. The class meets 100 minutes every week and 16 times in total in a semester corresponding to 2 credits.

This paper introduces the backward design process for redesigning the course, describes the course project and its related course problems, and reports the direct and indirect assessment results. Some issues indicated by the assessment results and lessons learned from the implementation of the redesigned course are discussed as well.

In general, we find that the instructional development and the assessment are well aligned with the learning outcomes after the course was implemented in the last autumn semester. Meanwhile, more objective and appropriate assessment methods are needed to assess problem-solving skills more effectively.

\section{Background}

Engineering education professional accreditation in China began in 2011. Since then, engineering programs in Chinese universities and colleges have attempted to adopt outcome-based education (OBE), reorganize the educational resources, and redesign curriculum according to the idea of OBE to meet the accreditation criteria. China's becoming an official member of the Washington Accord in 2016 marked the internationalization of China's engineering education professional accreditation. In the authors' home institution, a technical institution in the north of China, 17 engineering programs have passed the 
engineering education professional accreditation in China.

Between 2018 and 2019, the instructors redesigned a junior level engineering elective experimentation course, which is named Engineering Design and Practice for College Students (EDPCS). Prior to the redesign, the course had been offered for 14 years at the authors' institution. The redesign was conducted to better support the accreditation of engineering programs. As an elective experimentation course, EDPCS aims at enhancing students' practical skills by providing more and multiple practical opportunities in addition to the compulsory courses. In the author's institution, undergraduates are required to complete 4-6 credits of elective experimentation courses before graduation. The course reported in this paper is redesigned as an exemplar of the elective experimentation course which can support accreditation in multiple programs.

Prior to the redesign, the course had highlighted engineering operational skills, including hands-on making, experiment, and test and technical communication skills, especially technical writing skills, and it had been highly praised by students, who felt they achieved a lot in this course, and the course portfolios-including the articles written by students and the artifacts completed in the class - were very helpful in job search or applying for the enrollment of a graduate school.

The newly designed course was implemented for the first time in the fall semester of 2019 especially to promote students' problem-solving skills because problem-solving is considered as the essential capacity in ABET accreditation [2].

Problem-based learning (PBL) has proved an effective way of enhancing problem-solving skills in many different disciplines, especially in medicine and engineering. Problem-based Learning was first introduced at McMaster University in Canada, a pedagogy that stresses student-centered, small group learning (with teachers acting as facilitators) and organized around problems as specific attributes [3]. Since then, it has been widely used all around the world, and there are many successful cases of applying PBL in professional education.

Howard S. Barrows mentioned in his article that "PBL approaches and curricula have been developed in many other areas of education in professional schools (nursing, law, engineering), college-level courses, and kindergarten through 12th grade" [4] and list some examples reported in the literature. Donald R. Woods reported a new program in chemical engineering improved students' marks as well as their response to the learning environment, problem-solving skills, and lifetime learning skills [5]. Flemming K. Fink from Aalborg University in Denmark, one of the main advocates of PBL in the world, introduced their experience in establishing a university in a region with little industrial activities; Fink's work shows that PBL played an instrumental role in preparing an engineering workforce that stimulated the local economy and enhanced the region's global competence [6].

PBL is used as the signature pedagogy in the course reported in this paper, which is organized around three authentic engineering problems: temperature detection, amplification of a weak signal, and making a judgment to operate automatically. In addition, three warmup problems were assigned for scaffolding student learning. 


\section{The backward design process}

Following the guiding principle of letting students "solve problems as an engineer," the course instructors took a backward design [1] approach to redesign this course in three steps. First, learning outcomes for the course were redefined to highlight problem-solving skills, which are essential outcomes according to the ABET criteria. The redefined learning outcomes include 10 items as indicated in Table 1.

Table 1. Learning Outcomes for the course EDPCS

\begin{tabular}{|c|c|c|}
\hline Learning outcome items & $\begin{array}{l}\text { Corresponding } \\
\text { ABET criteria[2] }\end{array}$ & $\begin{array}{l}\text { Ability category } \\
\text { in the course }\end{array}$ \\
\hline $\begin{array}{l}\text { 1. An ability to solve authentic engineering } \\
\text { problems by applying principles of } \\
\text { engineering, mathematics, and science }\end{array}$ & \multirow{2}{*}{$\begin{array}{l}\text { An ability to identify, } \\
\text { formulate, and solve } \\
\text { complex engineering } \\
\text { problems by applying } \\
\text { principles of } \\
\text { engineering, science, } \\
\text { and mathematics }\end{array}$} & \multirow{2}{*}{$\begin{array}{l}\text { Problem-solving } \\
\text { skills (especially } \\
\text { engineering design } \\
\text { ability) }\end{array}$} \\
\hline $\begin{array}{l}\text { 2. An ability to calculate and decide the } \\
\text { parameter and put forward solutions that meet } \\
\text { the specified need by applying principles of } \\
\text { engineering, mathematics, and science }\end{array}$ & & \\
\hline $\begin{array}{l}\text { 3. An ability to assemble and make prototypes } \\
\text { and experiment devices using appropriate } \\
\text { tools and selecting appropriate components, } \\
\text { material, and parts. }\end{array}$ & Not in ABET criteria & \multirow{4}{*}{$\begin{array}{l}\text { Practical operation } \\
\text { skills }\end{array}$} \\
\hline $\begin{array}{l}\text { 4. An ability to plan an experiment and test } \\
\text { with appropriate instruments and apparatus }\end{array}$ & \multirow{3}{*}{$\begin{array}{l}\text { An ability to develop } \\
\text { and conduct } \\
\text { appropriate } \\
\text { experimentation, } \\
\text { analyze and interpret } \\
\text { data, and use } \\
\text { engineering judgment } \\
\text { to draw conclusions }\end{array}$} & \\
\hline $\begin{array}{l}\text { 5. An ability to record data and phenomena } \\
\text { objectively in the experiment, and interpret } \\
\text { the data and analyze the phenomenon to draw } \\
\text { a conclusion and recognize the issues. }\end{array}$ & & \\
\hline $\begin{array}{l}\text { 6. An ability to analyze and try to solve the } \\
\text { unexpected problems in the process of } \\
\text { adjustment and testing using test apparatus } \\
\text { and/or tool software. }\end{array}$ & & \\
\hline $\begin{array}{l}\text { 7. An ability to compose multiple genres of } \\
\text { professional technical documents. }\end{array}$ & \multirow{2}{*}{$\begin{array}{l}\text { An ability to } \\
\text { communicate } \\
\text { effectively with a } \\
\text { range of audiences }\end{array}$} & \multirow{2}{*}{$\begin{array}{l}\text { Technical } \\
\text { communication } \\
\text { skills }\end{array}$} \\
\hline $\begin{array}{l}\text { 8. An ability to communicate with public } \\
\text { orally and present one's opinion clearly. }\end{array}$ & & \\
\hline $\begin{array}{l}\text { 9. An ability to conduct scientific research } \\
\text { according to the methodology of scientific } \\
\text { research. }\end{array}$ & Not in ABET criteria & $\begin{array}{l}\text { The methodology } \\
\text { of scientific } \\
\text { research }\end{array}$ \\
\hline
\end{tabular}




\section{Learning outcome items}

10. An ability to acquire and apply new knowledge as needed, using appropriate learning strategies.

\section{Corresponding} ABET criteria[2]

Ability category

in the course

Lifelong learning

These ten learning outcomes are categorized into five domains of skills: problem-solving skills, practical operational skills, technical communication skills, the methodology of scientific research, and lifelong learning. This course particularly focused on developing students' problem-solving, practical operation, and technical communication skills (shaded in pink in Table 1).

Second, a comprehensive assessment plan including a direct assessment method and an indirect assessment method was created to measure student achievement in each learning outcome. Rubrics-based grading by the instructor as direct assessment [7] focuses on assessing five dimensions of student work: the solution's efficacy, quality of technical writing, oral communication, completion of prototypes, and testing plans and results. These assessment targets correspond to the three main categories of learning outcomes: problem-solving, practical orientation, and technical communication. The alignment of learning outcomes, direct assessment, and instructional design are shown in Fig. 1. In addition, a questionnaire was used as an indirect assessment of all the ten learning outcomes, including the methodology of scientific research and lifelong learning, which were not assessed in the direct assessment.

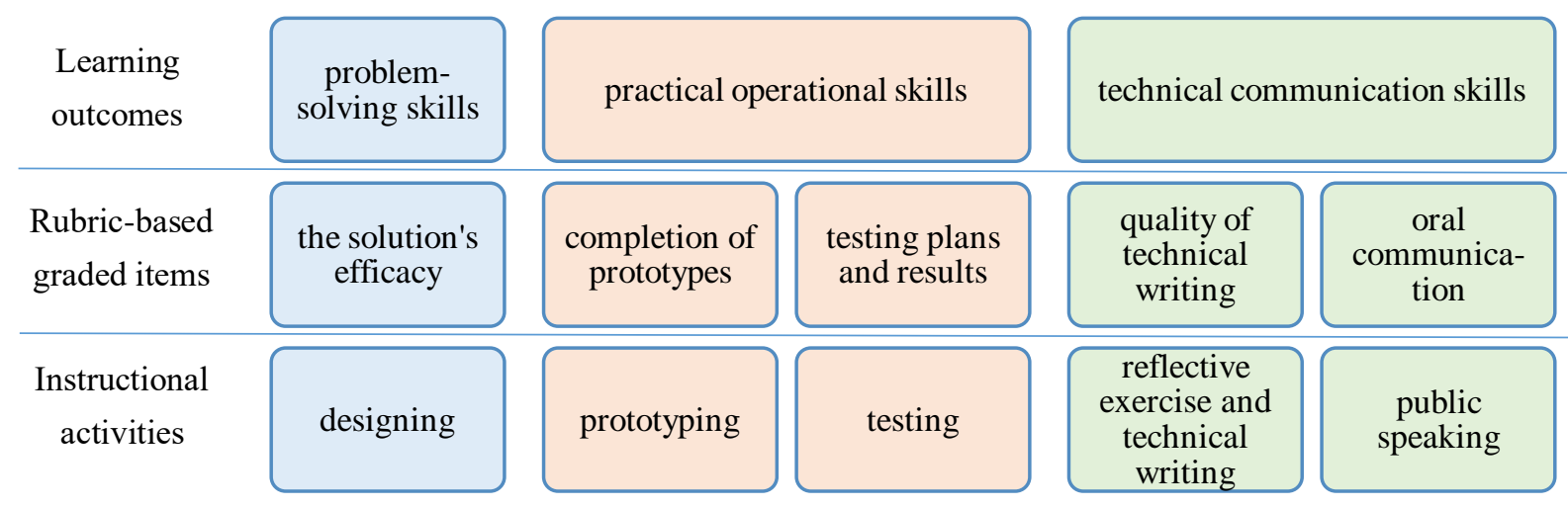

Figure. 1 The alignment of the learning outcomes, direct assessment items, and instructional activities

Finally, instructional activities including designing, prototyping, testing, written and oral communication, reflective exercise, as well as lectures. These activities are aligned with the newly developed learning outcomes and direct assessment plan as shown in Fig. 1. Also, these instructional activities also supported learning outcomes 9 and 10: the methodology of scientific research and lifelong learning. 


\section{Instructional design description}

In this course, students are required to complete a project of converting an electric soldering iron only with the function of heating into a temperature controllable one by the end of the semester. Its goal is to maintain the temperature of soldering iron at $350^{\circ} \mathrm{C} \pm 20^{\circ} \mathrm{C} \quad(662 \mathrm{~F} \pm 68 \mathrm{~F})$ using a series of detecting, measuring and controlling circuits. This project comes from authentic engineering problems - the application of automatically temperature controlling - and provides an opportunity for students to practice problem-solving skills in solving engineering problems and applying theoretical knowledge in engineering realities.

We provide the activator which can activate or deactivate the power supply of the soldering iron according to the input signal. What students need to do is to prepare a correct control signal which will be input into the activator. This work involves 3 steps as shown in Fig. 2: 1) obtaining the electric signal which representing current temperature of the soldering iron with sensors, 2) preparing an appropriate signal which can be used to judge if the temperature higher or lower than the setting value, and 3) obtaining an appropriate controlling signal for the activator to activate or deactivate the power supply.

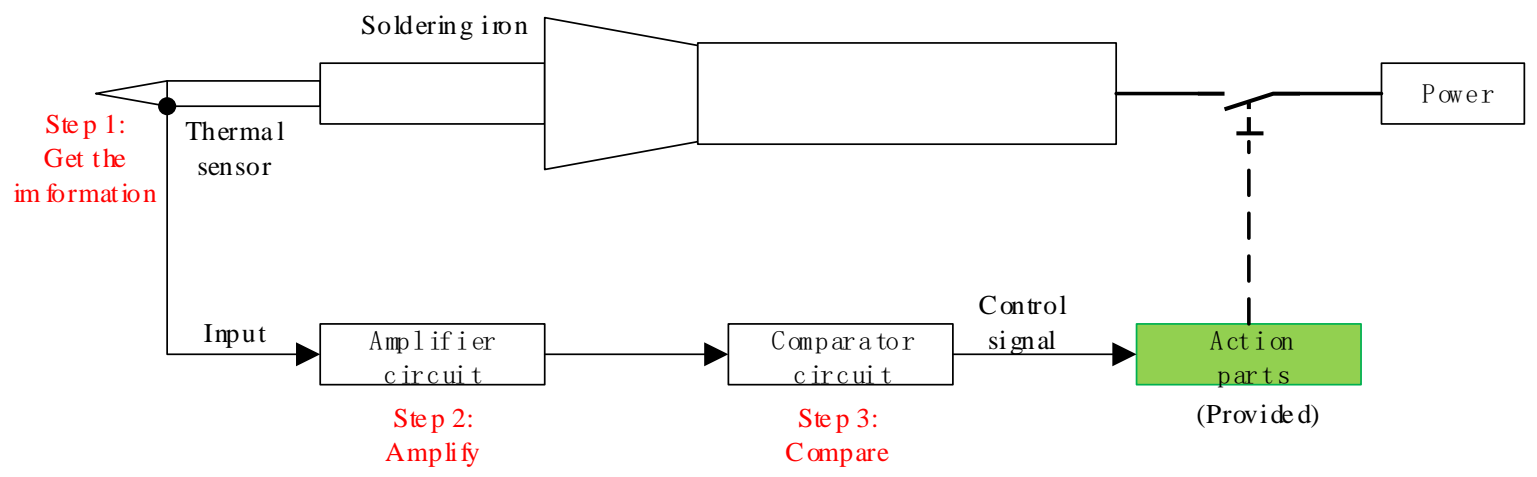

Figure.2 The diagram of the temperature controllable electronic soldering iron project

The three steps are three problems to be solved step by step, which are called authentic problems. In order to scaffold students to achieve the final goal successfully, three warmup problems are weaved into the interval of authentic problems. So the problems list as follows:

1) Warmup problem 1 - Design and make a capacitor charging and discharging circuit with the given components on the given Printed Circuit Board (PCB). Students are expected to practice the steps of solving a problem and become familiar with the complete procedure of designing, making and testing and all the components and materials provided for them to fulfill the task.

2) Authentic problem corresponding to Step 1 - How can you know the temperature of the electronic soldering iron which is the input of the upcoming circuit. Students are expected to solve a decision-making problem [8] using the steps of solving a problem 
including defining the problem, representing the problem with graphics, organizing the information known and unknown, comparing among a couple of available solutions, deciding the selected solution and evaluating its validity.

3) Warmup problem 2 - Design the layout of the given Series Circuit and Parallel Circuit on the given PCB. The purpose of this design problem [8] is to be familiar with the principle of layout on the given PCB and practice to design a layout according to the schematic.

4) Warmup problem 3 - Design and make a voltage amplifier circuit with the magnification of 101X using UA741 as the operational amplifier. This is a pilot design problem for step 2. Students are expected to transfer to the two-stage voltage amplifier circuit naturally after completing this warmup problem.

5) Authentic problem corresponding to Step 2 - Design and make a two-stage voltage amplifier circuit with the approximate magnification of 420X using UA741 as the operational amplifier. This is the key session of the project to prepare an adequate signal used in the next session for judgment.

6) Authentic problem corresponding to Step 3 - Design and make a voltage comparator circuit using UA741 outputting a signal of $+12 \mathrm{~V}$ or $0 \mathrm{~V}$ to control the activator when connected to it. The project will be completed and the temperature controllable electronic soldering iron will work if this problem is solved successfully.

All the teaching and learning activities in the course are organized around the problems inside the frame of completing the project, and each class is a small step toward solving all the above problems and completing the project finally. Students' learning is like working in the authentic workplace as an engineer including designing, hands-on prototyping, testing, technical communication, as well as reflective exercises. Students complete the part of hands-on work in class, such as soldering the circuits modules, testing with a multi-purpose meter to examine the modules and doing some experiments, and the section of presentation which is the pathway to achieve the learning outcome of technical communication. Also, they are required to complete a series of technical writings on the basis of reflective exercises after class and prepare for the next class as well, as shown in Fig. 3. Most of the topics of technical writings are designing a kind of meter using the circuit model practiced in class in order to show students how to apply the knowledge and skills practiced in class into solving a real engineering problem.

In the process of the course, students are required to solve problems 1-5 individually and problem 6 in a group and each one will have at least one opportunity to present in class. At the end of the course, a series of design solutions presented in technical writings and a completed prototype will be a student's portfolio representing the achievement of learning outcomes. 


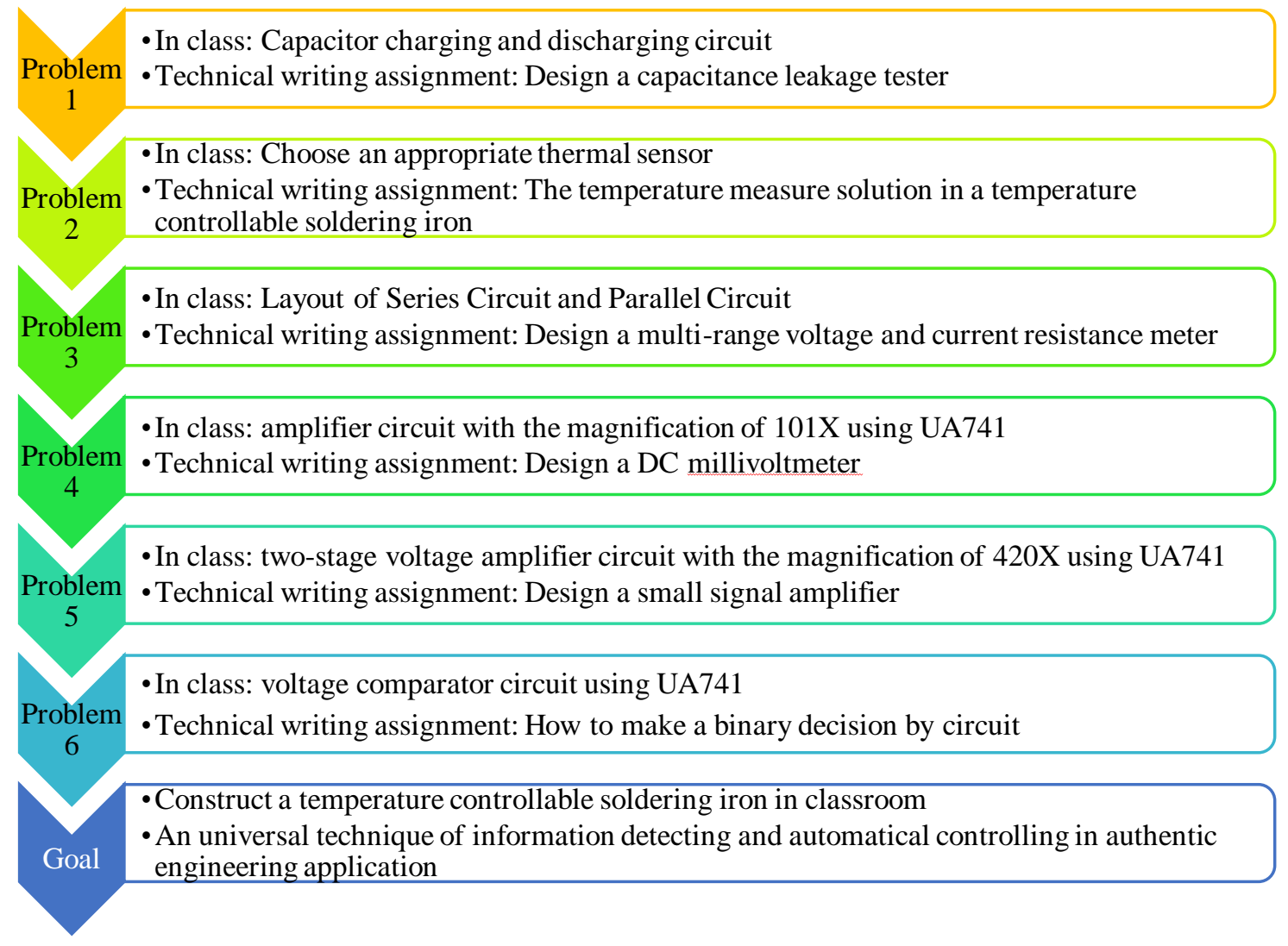

Figure. 3 Topics of technical writing corresponding to the problems to be solved

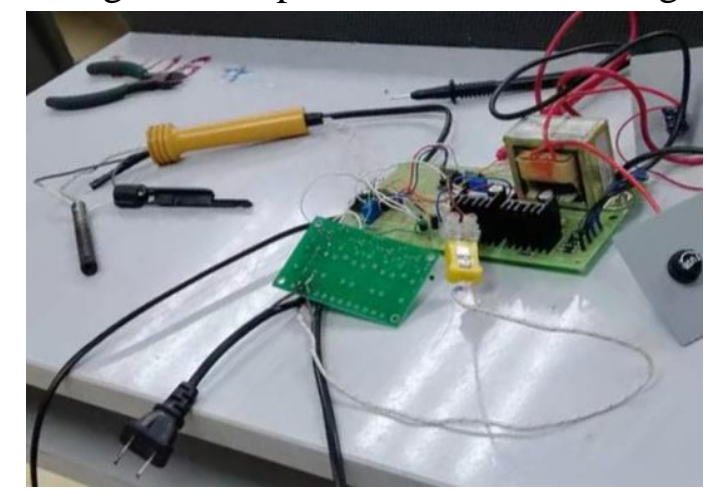

(a) The final project artifact

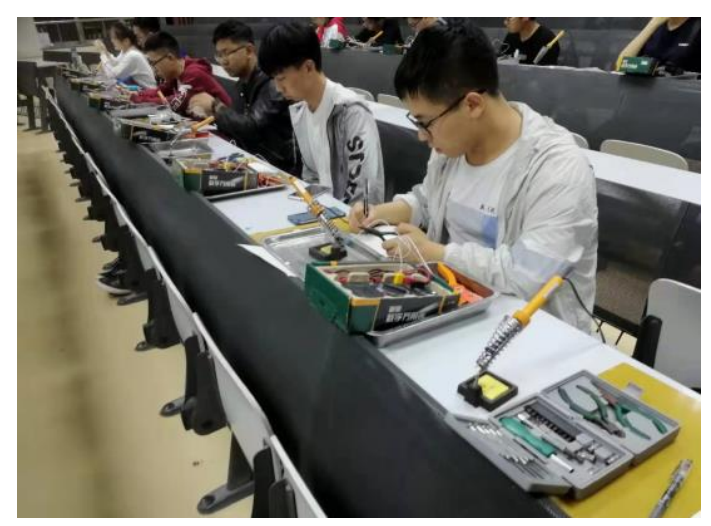

(c) Experiment on problem 2

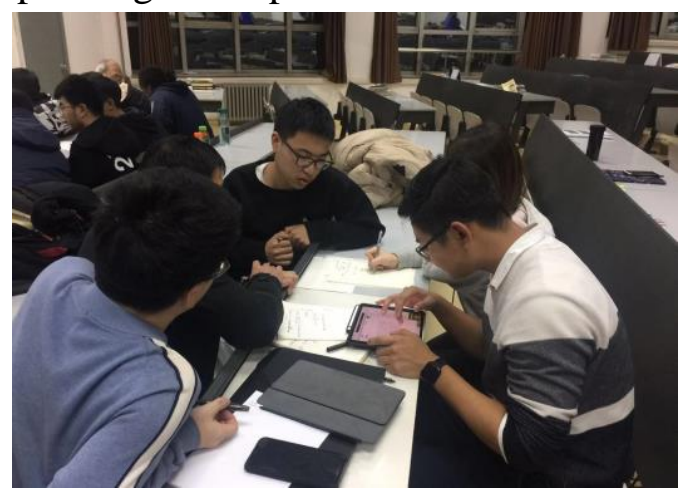

(b) Teamwork on the solution for problem 6

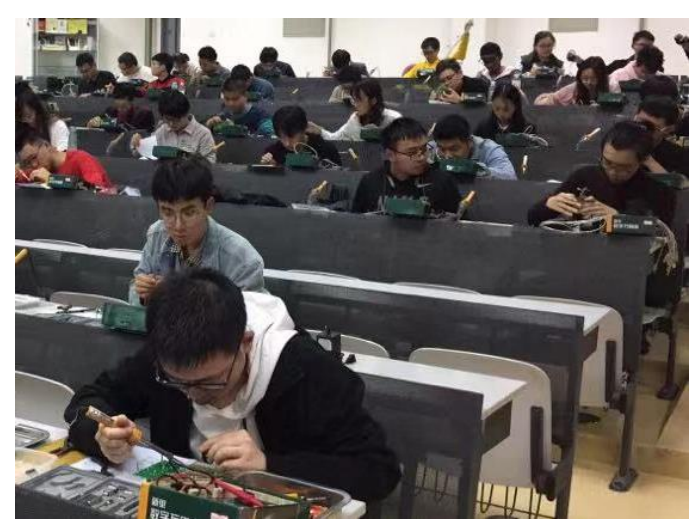

(d) Hand-on making

Figure. 4 The artifact and the scenario in class 
Fig. 4 shows the artifact completed by a group and the scenario in which students were working in class. The learning environment is equipped with necessary sensors, electronic components, assembling materials, operating tools, and testing platforms.

The instructor of the redesigned course has 7 years' experience of teaching the former version of the same course. Her teaching excellence and engineering problem-solving skills can be testified by the winning of first prize in the National Mechanical Innovative Designing Competition in China. The instructor acted as a facilitator, not a lecturer or a teacher, who guided the student-centered active learning by using Problem-Based Learning pedagogy and gave students professional feedback and advice.

\section{Assessment results}

27 students completed the course and received a grade from the instructor during the fall semester of 2019. In addition, two students failed in completing the course, including an international (non-Chinese) student. The average and standard deviation of each direct assessment dimension are listed in Table 2.

Table 2: The average and standard deviation of the five assessment dimension

\begin{tabular}{|l|l|c|c|}
\hline \multicolumn{1}{|c}{$\begin{array}{c}\text { Learning } \\
\text { outcomes } \\
\text { category }\end{array}$} & \multicolumn{1}{c}{$\begin{array}{c}\text { Direct assessment dimension } \\
\text { Problem-solving } \\
\text { skills }\end{array}$} & The solution's efficacy (5' in total) & $\begin{array}{c}\text { Standard } \\
\text { deviation }\end{array}$ \\
\hline $\begin{array}{l}\text { Practical } \\
\text { operational skills }\end{array}$ & Completion of prototypes (20' in total) & 19.5 & 0.49 \\
\hline & Testing plans and results (15' in total) & 14.8 & 0.64 \\
\hline $\begin{array}{l}\text { Technical } \\
\text { communication } \\
\text { skills }\end{array}$ & Quality of technical writing (55' in total) & 47.5 & 6.98 \\
\hline & Oral communication(5' in total) & $48.3^{*}$ & $5.61^{*}$ \\
\hline
\end{tabular}

Data with ${ }^{*}$ in the table is the statistic result excluding the only one international student because he has difficulty in speaking and writing in Chinese, while the course was delivered in Chinese.

The counting numbers of students on all the score levels in the five assessment dimensions are shown in Fig. 5, in which the score level between $90 \%$ and $100 \%$ can be considered as grade A, and the following four score levels can be considered as $\mathrm{B}, \mathrm{C}$, and $\mathrm{D}$, and $\mathrm{F}(<60 \%)$. According to the rubrics, the learning outcomes can be considered achieved when the score is above $60 \%$, and the higher the score level, the better a learning outcome is achieved. 
According to the assessment results, the learning outcomes are achieved by all but two students (one international student failed in technical writing and oral communication). And the course maintained a traditional strength on practical operational skills which can be seen from the 100 percent of level A in completion of prototype and testing plans and results.

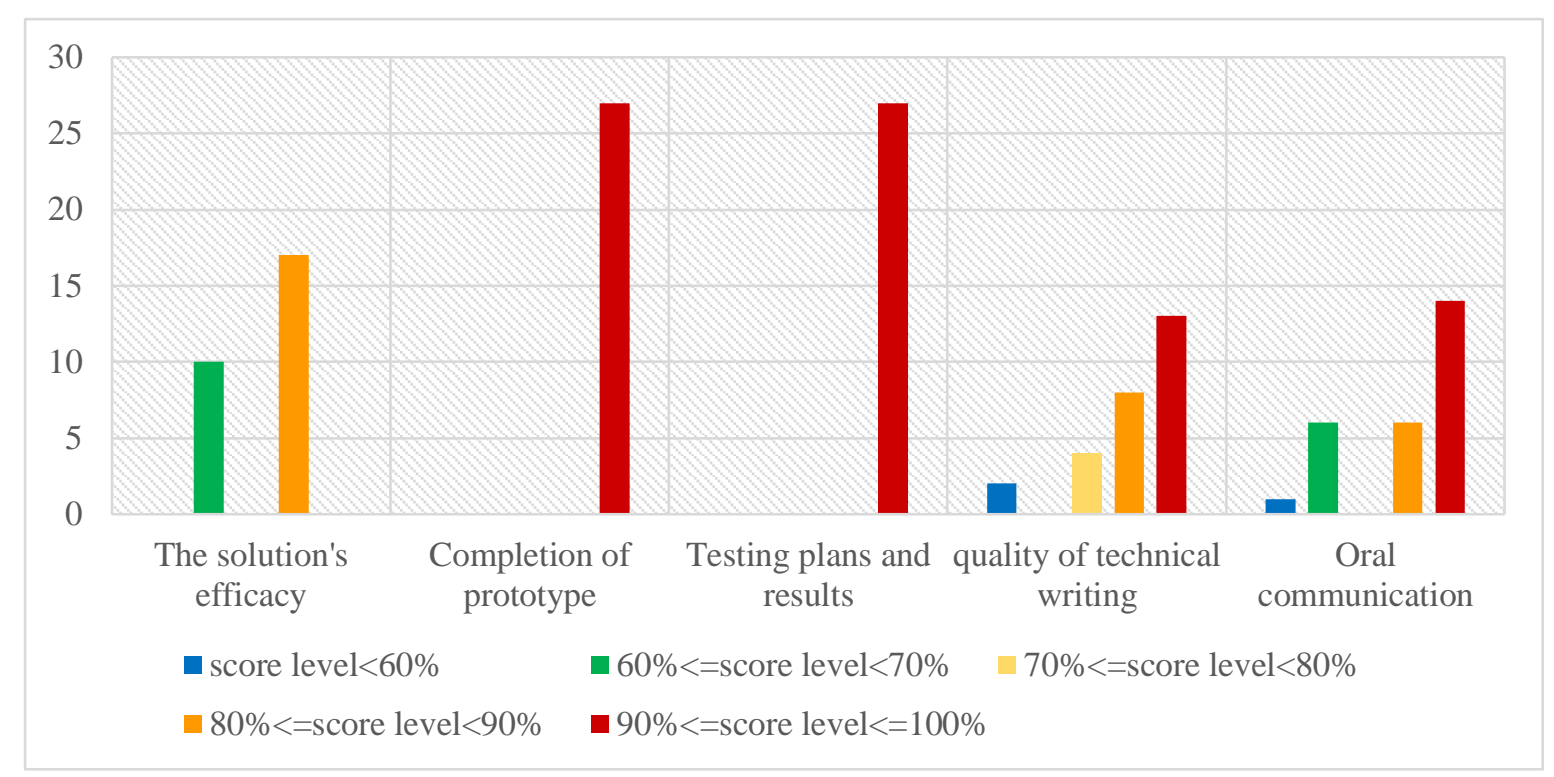

Figure. 5 The number of students on different score levels in five assessment dimensions.

Besides direct assessment, the authors also administrated a survey to assess students' self-perceived achievement of learning outcomes 1-10. 25 students completed the self-report survey online. The questionnaire consists of two parts. The first part is a Likert-scale for the self-report on the learning outcomes including 10 items corresponding to the 10 learning outcomes listed in Table 1. The students are asked to share the extent to which the course helped them achieve the 10 learning outcomes using a 5 point Likert scale, where 1 means "No help at all" and 5 means "Help very greatly". On the whole, up to 80 percent of students reported that the course "helped them a lot" or "very greatly" in achieving all the 10 learning outcomes, as shown in Fig. 6 . And up to $96 \%$ of all the students thought they achieved in all the ten learning outcomes more or less (up to "have a lot of help"). 


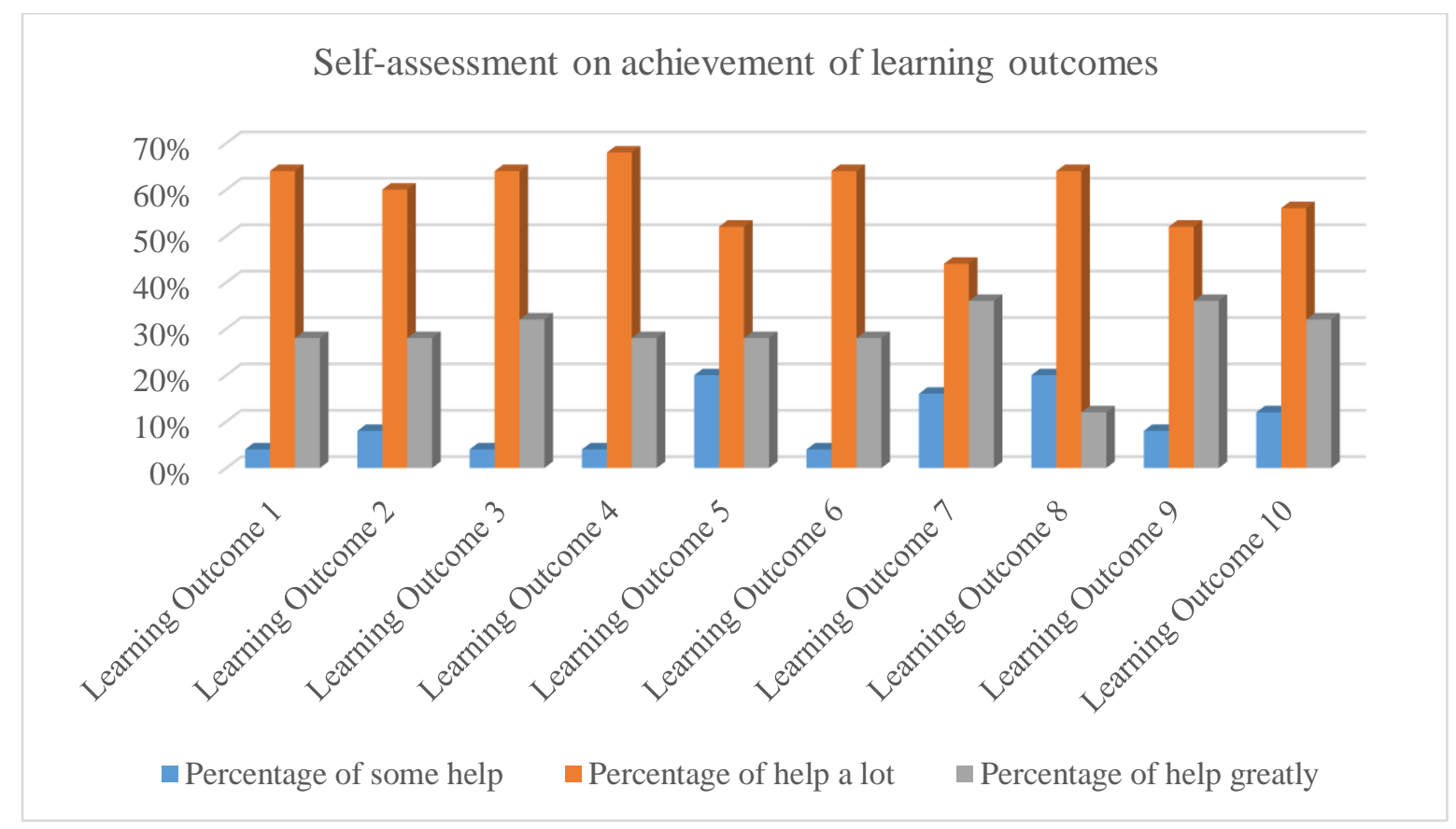

Figure. 6 Results of self-reported achievement of learning outcomes.

The second part is to identify the three most significant learning outcomes from students' perspectives. Learning outcomes 7 (An ability to compose multiple genres of professional technical documents) is named as the most significant learning outcomes by being referred 11 times in 25 students, and the second place is learning outcome 1 (An ability to solve authentic engineering problems by applying principles of engineering, mathematics, and science) referred 10 times. Learning outcome 3 (An ability to assemble and make prototypes and experiment devices using appropriate tools and selecting appropriate components, material, and parts) and 6 (An ability to analyze and try to solve the unexpected problems in the process of adjustment and testing using test apparatus and/or tool software) share third place with the same referring frequency of 9. Fig. 7 shows the frequency of all the learning outcomes referred by students. 


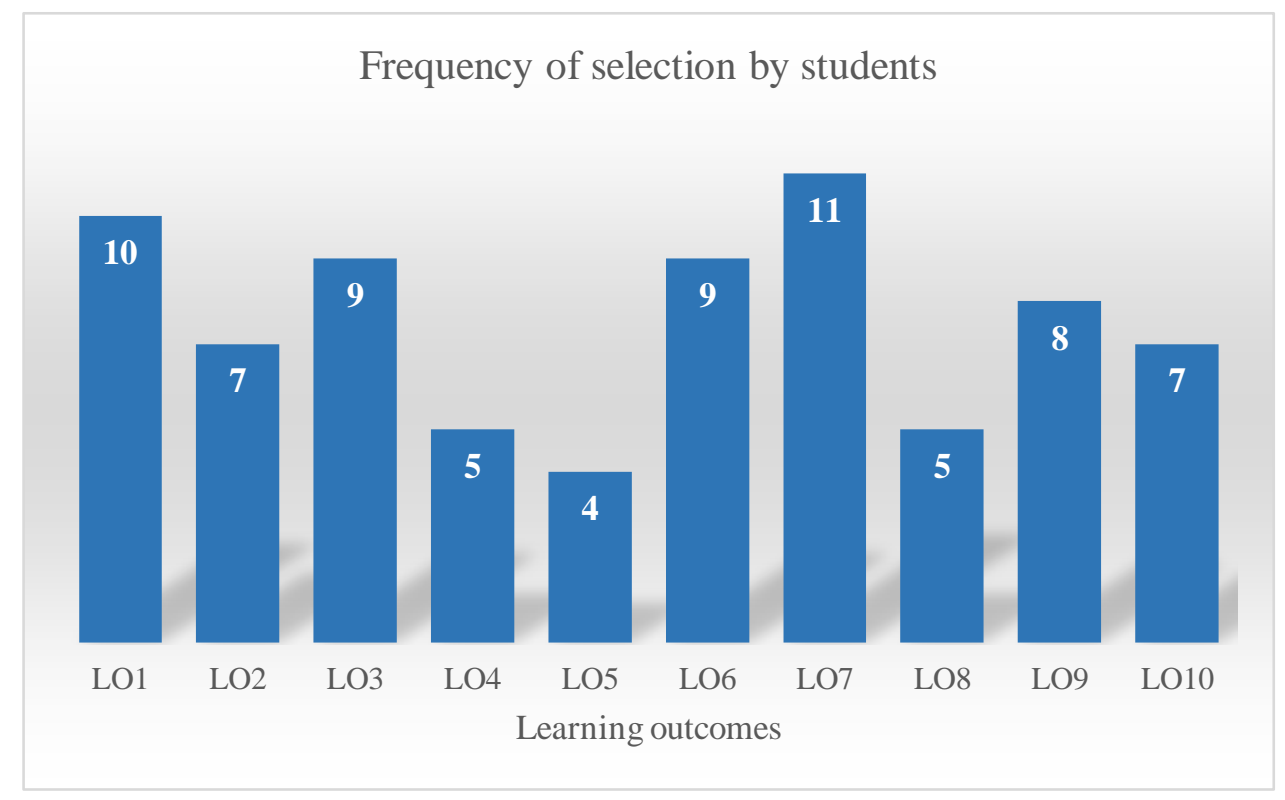

Figure. 7 Three most significant learning outcomes from students' perspectives

While the most significant learning outcome identified by the instructor is learning outcome 1(An ability to solve authentic engineering problems by applying principles of engineering, mathematics, and science), which differs slightly from students' perspective.

\section{Discussion}

It can be seen from the assessment result above that the redesigned course retained the traditional strength in technical writing and practical operation skills. Meanwhile, while students were satisfied with their improvement in problem-solving skills, the solutions' efficacy did not strongly meet the instructor's expectations. There can be several interpretations of this discrepancy: First, there might be a gap between the instructor's and students' expectations of problem-solving skills. Second, there might be space for continuously improving the instructor's coaching of problem-solving. However, we propose that the discrepancy also points to a more fundamental problem in assessing problem-solving skills, namely, whether problem-solving skills can be appropriately assessed through the efficacy of student solutions. Literature suggests problem-solving as a series of actions taken in a structured process [9]. Compared with this process-based framing of problem-solving, the solution is just one, although the ultimate, step in the process. The challenge of assessing students' problem-solving skills more accurately is also a general challenge for evaluating this redesigned course. We report some thoughts for future work here.

Researchers at Clemson University have developed an assessment tool for problem-solving skills named PROCESS, which is also a scaffold for students to learn and exercise problem-solving skills [10]. The rubrics of the PROCESS can be used to grade how students perform in the process of solving a problem and can track the improvement of problem-solving skills over time. In our future work, the authors plan to use the PROCESS 
tool to assess students' problem-solving skills during the next offer of this course. In the current study, we piloted the PROCESS tool as a part of our student survey.

The self-assessment questionnaire mentioned above contained questions on students' experience following a structured process of problem-solving to complete the temperature controlling project. The questions originated from the PROCESS assessment tool for problem-solving skills and were modified to fit the redesigned course. Students are required to grade between 0-10 (0 represents "not at all", while 10 represents "absolutely") for each question's statement according to their own situation and experience.

It is learned from the survey that the students have the fundamental and necessary knowledge, practical and experimental skills in solving the problems involved in this project, and the workload is not too much for them from students' perspective. The average score of the statement "I can solve similar engineering problems in the future, for example, temperature control problems applied in another context, or problems to detect some other physical quantity and control it automatically" is 6.92 , which means that students are generally confident with themselves in solving a similar problem. This value will be more meaningful if a pre-post test is executed. So, more research on using effective assessment methods of problem-solving skills, for example, the PROCESS tool, and their results need to be done in the future to improve the redesigned course continuously.

In the process of implementing the redesigned course, the authors also noticed that all the students from different engineering majors can perform well despite their difference in the knowledge of electronics, in part because the core problem to be solved in this course is originated from the information detection technology, which is widely used in many engineering disciplines, even though this course was redesigned for juniors with the necessary fundamental knowledge of electronics. So we suggest that the redesigned course can adapt to multiple engineering programs including electronic and computer engineering, mechanical engineer, aerospace and aviation engineering, material engineering, bioengineering, and so on.

\section{Conclusion}

This paper reported the backward design with Problem-Based Learning pedagogy and the comprehensive assessment result of a redesigned experimentation course to support the accreditation in China. In general, it can be testified that the instructional development and the assessment are aligned with the learning outcomes after the course was implemented in the last autumn semester, while more objective and reasonable assessment methods need to be used to assess problem-solving skills more effectively.

This work is important as it reports one of the few examples of systematically applying PBL and the ABET criteria in redesigning an engineering experimentation course in China. The paper discusses lessons from adopting ABET student outcomes in an international context 
and provides a case study for the international dissemination of educational standards in engineering. 


\section{References}

[1] Grant P. Wiggin and Jay McTighe, "Backward design," in Understanding by Design, Alexandria: Association for Supervision and Curriculum Development, 2005, pp. 13-34.

[2] ABET, Criteria for Accrediting Engineering Programs. Baltimore, MD: ABET, 2018.

[3] E. D. Graaff and A. Kolmos, "Characteristics of Problem-Based Learning,"

Interdisciplinary Journal of Engineering Education, vol. 19, no. 5, pp. 657-662, 2003.

[4] Howard S. Barrows, "Problem-Based Learning in Medicine and Beyond: A Brief Overview," in Bring Problem-Based Learning in Higher Education: Theory and Practice, L. Wilkerson and W. H. Gijselaers, Ed. San Francisco: Jossey-Bass, 1996, pp. 3-12.

[5] Donald R. Woods, "Problem-Based Learning for Large Classes in Chemical Engineering," in Bring Problem-Based Learning in Higher Education: Theory and Practice, L. Wilkerson and W. H. Gijselaers, Ed. San Francisco: Jossey-Bass, 1996, pp. 91-99.

[6] F. K. Fink, "Problem-Based Learning in engineering education: a catalyst for regional industrial development," World Transactions on Engineering and Technology Education, vol. 1, no. 1, pp. 29-32, 2002.

[7] Joni E. Spurlin, “Assessment methods used in undergraduate program assessment," in Design Better Engineering Education through Assessment, Joni E. Spurlin, Sarah A. Rajala, and Jerome P. Lavelle, Ed. Sterling: Stylus, 2008, pp. 59-116.

[8] D. H. Jonassen, “Toward a Design Theory of Problem Solving," ETR\&D, vol. 48, no. 4, pp. $63-85,2000$.

[9] Sarah J. Grigg and Lisa Benson, "Promotion Problem Solving Proficiency in First-Year Engineering: PROCESS Assessment," in 122 ${ }^{\text {nd }}$ ASEE Annual Conference \& Exposition, Seattle, WA, USA, June 14-17, 2015.

[10] Sarah J. Grigg, Jennifer Van Dyken, Lisa Benson, and Beshoy Morkos, "Process Analysis as a Feedback Tool for Development of Engineering Problem Solving Skills," in $120^{\text {nd }}$ ASEE Annual Conference \& Exposition, Atlanta, GA, USA, June 23-26, 2013. 